Manuelle Medizin 2016 · 54:422

DOI 10.1007/s00337-016-0213-9

(C) Springer-Verlag

Berlin Heidelberg 2016

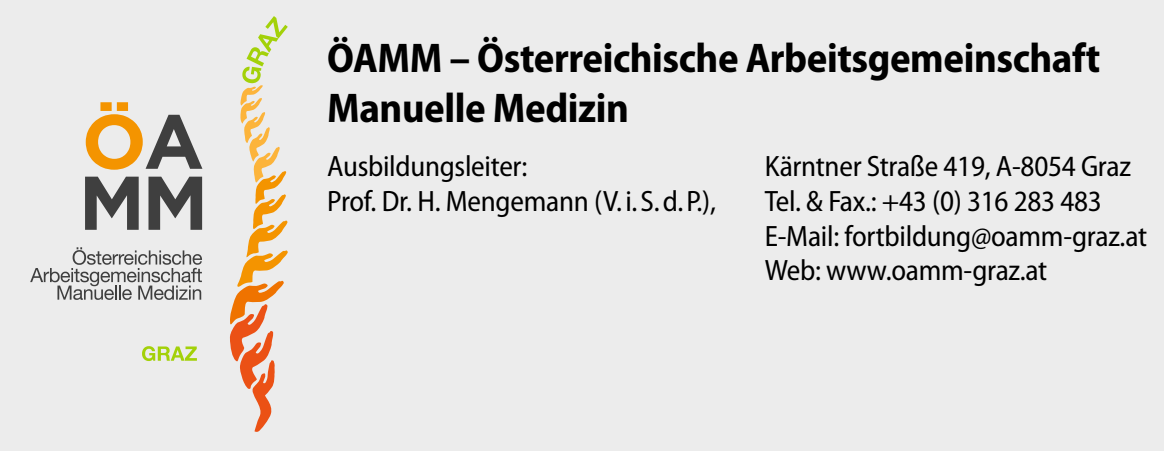

\section{Kurse 2016}

\section{Kurse}

26.11.2016-03.12.2016

RE Wochenende

12.11.2016-13.11.2016

\section{Kurse 2017}

Kurs I

21.01.-28.01.2017

01.04.-08.04.2017

14.10.-21. 10.2017

Kurs II

07.01.-14.01.2017

13.05.-20.05. 2017

24.06.-01.07.2017

Kurs III

22.04.-29.04. 2017

30.09.-07. 10.2017

11.11.-18.11.2017

\section{Kurs IV}

04.02.-11.02.2017

02.12.-09.12.2017

\section{Kurs V}

06.05.-13.05. 2017

02.12.-09.12.2017

\section{Refresher Woche}

13.03.-17.03.2017

Refresher Wochenende

25.11.-26.11.2017
Loipersdorf

KA1661

Graz

KA1631

Kurs.-Nr.

Wien KA1711

Graz KA1712

Bad Häring KA1713

Graz KA1714

$\begin{array}{ll}\text { Graz } & \text { KA1721 } \\ \text { Wien } & \text { KA1722 } \\ \text { Graz } & \text { KA1723 } \\ \text { Bad Häring } & \text { KA1724 }\end{array}$

$\begin{array}{ll}\text { Bad Häring } & \text { KA1731 } \\ \text { Graz } & \text { KA1732 } \\ \text { Wien } & \text { KA1733 } \\ \text { Graz } & \text { KA1734 }\end{array}$

Graz KA1741

Graz KA1742

$\begin{array}{ll}\text { Graz } & \text { KA1751 } \\ \text { Graz } & \text { KA1752 }\end{array}$

St. Johann KA1771

Loipersdorf KA1761

\section{Ausbildungsziel}

Das Erlernen von klinisch-manuellen Untersuchungstechniken am Stütz- und Bewegungssystem zur therapeutischen Beeinflussung von reversiblen Funktionsstörungen.

Die Fortbildung dient damit der Erweiterung des Angebotes der kurativen, rehabilitativen und präventiven Medizin.

\section{Zielgruppe}

ÄrztInnen für Allgemeinmedizin und FachärztInnen aller Sonderfächer.

\section{Teilnahmevoraussetzung}

Frühest möglicher Beginn der Fortbildung ist nach der Promotion.

\section{Weiterbildungsdauer/Stundenerfordernis}

Mindestens 1,5 Jahre, nach den Richtlinien der Österreichischen Ärztekammer sind für das ÖÄK Diplom Manuelle Medizin insgesamt 300 Fortbildungsstunden (100 Stunden Theorie, 200 Stunden Praxis und Demonstrationen) erforderlich.

\section{Wesentliche Inhalte}

Erkennen und Behandeln mit den Händen

Von der Arbeitshypothese zur Diagnose

Prävention

Rezidivprophylaxe

Terminänderungen/Absagen vorbehalten.

Wir weisen darauf hin, dass für die Kursteilnehmer der ÖAMM die Kurszeiten und Anwesenheitspflicht bindend sind!

Die Bestätigung der Fortbildungspunkte durch die österreichische Ärztekammer ist an die Erfüllung der Kursrichtlinien gebunden.

Verbindliche Anmeldungen und Auskünfte im Sekretariat der ÖAMM

E-Mail: fortbildung@oamm-graz.at Internet: www.oamm-graz.at Adresse: Kärntner Straße 419, 8054 Graz

Tel. \& Fax: +43 (0) 316-283 483 